\title{
XPERT MYCOBACTERIUM TUBERCULOSIS/RIFAMPICIN ASSAY: A BOON IN TUBERCULOSIS DIAGNOSTICS
}

\author{
KAVYA RAMAMURTHY, SEVITHA BHAT*, SHALINI SHENOY, ASEEM RANGNEKAR
}

\author{
Department of Microbiology, Kasturba Medical College, Mangalore, Karnataka, India. Email: sevitha@rediffmail.com
}

Received: 07 June 2016, Revised and Accepted: 10 June 2016

\section{ABSTRACT}

Objectives: Mycobacterium tuberculosis (MTB) remains one of the most significant causes of mortality and morbidity in developing countries especially India. India has the highest burden of TB, with an estimated incidence figure of 2.1 million cases out of the 9 million cases of TB globally. Diagnosis of TB relies on conventional microscopy and culture with drawbacks related to sensitivity, specificity, turn around time (TAT). The aim of this study was to evaluate the performance of Xpert MTB/rifampicin (RIF) assay (GX) for MTB detection in pulmonary and extrapulmonary clinical samples.

Methods: A total of 209 clinical specimens (182: pulmonary and 27: extrapulmonary) were processed using auramine smear, culture by mycobacteria growth indicator tube and GenXpert.

Results: The sensitivity of GenXpert was $62.63 \%$ for pulmonary and $55 \%$ for extrapulmonary samples. The sensitivity and specificity of GX were $100 \%$ for the smear positive cases. The sensitivity, specificity, positive predictive value, and negative predictive value of the GX for smear negative cases were $67.8 \%, 97.5 \%, 90.4 \%$, and $89.6 \%$, respectively. RIF resistance was detected in 3.8\% the samples.

Conclusion: GenXpert, with short TAT, high sensitivity, specificity and less technical expertise required is a promising tool in TB diagnostics for the future.

Keywords: GenXpert, Tuberculosis diagnosis, Molecular method, Rifampicin resistance.

(C) 2016 The Authors. Published by Innovare Academic Sciences Pvt Ltd. This is an open access article under the CC BY license (http://creativecommons. org/licenses/by/4. 0/) DOI: http://dx.doi.org/10.22159/ajpcr.2016.v9i5.13315

\section{INTRODUCTION}

Tuberculosis (TB) is a transmissible infection caused by Mycobacterium TB (MTB) and is still one of the biggest challenges for developing countries. The most common form of TB is pulmonary TB. Extrapulmonary TB includes TB of lymph nodes, pleura, abdomen, bone and joint, spinal cord, and the brain [1].

TB remains a public health problem worldwide. The number of new cases reported every year globally is 8.7 million, and a number of deaths reported annually due to TB is 1.4 million [2]. TB accounts for $95 \%$ of deaths in resource poor countries and is among the top 5 causes of death in women aged 15-44 years [3].

Back home, the situation is worse. India bears the highest TB burden in the world. India accounts for 2.2 million cases of TB annually of the 9 million cases reported globally. $40 \%$ of the Indian population is infected with TB, the majority being latent TB [4].

Emergence of drug resistance is a major hurdle for TB control. The common reasons for the development of drug resistance include incorrect prescription, irregular supply of drugs, non-compliance of treatment, and lack of follow-up. Multidrug-resistant TB (MDR TB) is more difficult to treat. The rate of MDR TB in India is 2.1\% [5]. Thus, the need of the hour is to improve on TB diagnostics, which can give fast accurate results.

The diagnosis of TB relies on conventional microscopy, culture, and molecular assays.

Smear microscopy is a rapid, inexpensive test, but is associated with poor sensitivity and poor positive predictive value (PPV). Culture is the gold standard but it requires 2-8 weeks.

The early accurate diagnosis of TB is essential for control. Rapid diagnosis of TB depends on nucleic acid amplification techniques.
The major advantages of the molecular assays are high sensitivity and specificity and rapid turn around time (TAT) [6].

The WHO has implemented the use of GeneXpert MTB/rifampicin (RIF) assay for national TB program in developing countries [2]. GeneXpert MTB/RIF assay has been recently introduced by Cephid (Sunnyvale, CA, USA). The assay is based on the principle of real-time polymerase chain reaction. The automated assay can identify MTB and detect RIF resistance directly from the clinical specimen in 2-3 hrs [7].

This study undertaken focuses on the utility of GeneXpert MTB/RIF assay as a tool in the diagnosis of TB in our setting.

Aim

To evaluate the performance of Xpert MTB/RIF assay in the diagnosis of TB.

\section{OBJECTIVES}

- $\quad$ To study the sensitivity and specificity of Xpert MTB/RIF assay in the diagnosis of pulmonary and extrapulmonary TB

- To compare the performance of Xpert MTB/RIF assay with acid-fast bacilli culture

- To study the rate of RIF resistance in MTB isolates.

\section{METHODS}

The retrospective observational study was taken up by the Department of Microbiology, KMC Hospital, Ambedkar Circle, Mangalore. 209 patients with clinical suspicion and/or radiological evidence of TB were included in this study period of $1 \frac{1}{2}$ year duration from June 2014 to December 2015.

Out of the 209 samples studied, 182 were pulmonary and 27 were extrapulmonary samples. Pulmonary samples included sputum, 
bronchoalveolar lavage, and pleural fluid. Extrapulmonary samples studied included urine, fluids other than pleural fluid and biopsy specimen.

\section{Processing of samples}

Sputum and non-sterile specimen require decontamination and concentration.

- Petroff's method

- $\quad \mathrm{N}$-acetyl-L-cysteine $+2 \% \mathrm{NaOH}[8]$.

\section{Diagnostic methods}

1. Microscopy: Auramine staining for fluorescence microscopy

2. Culture of sample by rapid mycobacteria growth indicator tube. Positive cultures were identified with TBc identification test - detected by lateral flow immunochromatographic assay to detect the MPB 64 antigen [9]

3. GeneXpert MTB/RIF assay: Samples were processed as per kit insert.

\section{Data analysis}

Data collected will be entered into Microsoft Excel and analysis will be done by Statistical Package in Social Science version 16.0.

The sensitivity and specificity of the test were calculated using formula.

The study has received clearance from the Institutional Ethics Committee.

\section{RESULTS}

Ofthe 209 samples, 182 were pulmonary samples and 27 extrapulmonary samples with clinical, radiological, and histopathological suspicion of TB. Comparison of sensitivity of the diagnostic methods in pulmonary and extrapulmonary TB are shown in Tables 1 and 2. The performance of GeneXpert MTB/RIF assay is shown in Table 3.

Table 1: Comparison of sensitivity of diagnostic methods in pulmonary TB $(n=182)$

\begin{tabular}{lll}
\hline Method & Number of samples & Sensitivity (\%) \\
\hline Smear positive & 90 & 49.45 \\
Culture positive & 109 & 59.8 \\
Xpert positive & 114 & 62.63 \\
\hline
\end{tabular}

TB: Tuberculosis

Table 2: Comparison of sensitivity of diagnostic methods in extrapulmonary TB $(n=27)$

\begin{tabular}{lll}
\hline Method & Number of samples & Sensitivity (\%) \\
\hline Smear positive & 11 & 40.7 \\
Culture positive & 13 & 48 \\
Xpert positive & 15 & 55 \\
\hline
\end{tabular}

TB: Tuberculosis

Table 3: Evaluation of GeneXpert MTB/RIF assay in the diagnosis of TB according to MGIT culture results

\begin{tabular}{lllllll}
\hline & \multicolumn{2}{l}{ Smear positive } & & \multicolumn{2}{l}{ Smear negative } & Total \\
\cline { 2 - 3 } & $\begin{array}{l}\text { Culture } \\
\text { positive }\end{array}$ & $\begin{array}{l}\text { Culture } \\
\text { negative }\end{array}$ & & $\begin{array}{l}\text { Culture } \\
\text { positive }\end{array}$ & $\begin{array}{l}\text { Culture } \\
\text { negative }\end{array}$ & \\
\hline $\begin{array}{l}\text { GeneXpert } \\
\text { positive }\end{array}$ & 101 & 0 & 19 & 09 & 129 \\
$\begin{array}{l}\text { GeneXpert } \\
\text { negative }\end{array}$ & 0 & 0 & 2 & 78 & 80 \\
Total & 101 & 0 & 21 & 87 & 209 \\
\hline
\end{tabular}

TB: Tuberculosis, MTB/RIF: Mycobacterium tuberculosis/rifampicin, MGIT: Mycobacteria growth indicator tube
Table 3 data show that GeneXpert MTB/RIF assay was more sensitive than smear microscopy and culture.

The sensitivity and specificity of GeneXpert MTB/RIF assay in smear positive cases were $100 \%$. The sensitivity of GeneXpert MTB/RIF assay for smear negative samples was $67.85 \%$. Specificity of GeneXpert MTB/RIF assay for smear negative cases was $97.5 \%$. The PPV and negative predictive value were $90.4 \%$ and $89.6 \%$, respectively. Rate of RIF resistance was $3.8 \%$

\section{DISCUSSION}

Prompt diagnosis is essential for effective treatment and to limit the emergence and spread of MDR TB.Xpert MTB/RIF assay is the diagnostic tool which offers accurate results in $<2$ hrs GeneXpert MTB/RIF assay had the highest sensitivity of $62.63 \%$ compared to smear and culture, and thus, GeneXpert MTB/RIF assay outperformed the fluorescence smear microscopy examination, a finding consistent with the previous studies [10].

The sensitivity and specificity were $100 \%$ for GeneXpert MTB/RIF assay in smear positive cases. The sensitivity and specificity of GeneXpert MTB/RIF assay were $67.8 \%$ and $97.5 \%$, respectively, in smear-negative cases. The sensitivity of Xpert MTB/RIF assay reported in earlier studies was $57-76.9 \%$ in smear-negative, culture-positive pulmonary TB and $98-100 \%$ in smear-positive, culture-positive pulmonary TB cases. The specificity reported in previous studies was $99-100 \%$. The finding in our study is consistent with the study done by Zeka et al. [11].

Nine additional cases were diagnosed by GeneXpert MTB/RIF assay as positive, which were smear negative and culture negative. Xpert assay could pick up additional 9 cases compared to microscopy and culture, as reported earlier [12].

The sensitivity of Xpert MTB/RIF assay in detecting RIF resistance was $94.4-100 \%$ and the specificity was $98.3-100 \%$, according to the earlier reports $[13,14]$.

In our study, 8 samples (3.8\%) were RIF resistant as detected by GeneXpert MTB/RIF assay, but we have not confirmed the results of RIF resistance by drug susceptibility testing.

Thus GeneXpert MTB/RIF assay is a boon in TB diagnostics offering rapid identification of MTB in the clinical specimen with the added advantage of detection of RIF resistance in a single test.

\section{CONCLUSION}

GeneXpert MTB/RIF assay is a boon to TB diagnostics especially in countries like India. In this study, the sensitivity and specificity of GeneXpert MTB/RIF assay were much higher compared to microscopy and culture especially in smear positive, culture positive pulmonary samples. The added advantage of Xpert MTB/RIF assay is rapid TAT and less expertise required.

\section{ACKNOWLEDGMENTS}

The authors are grateful to Manipal University for all the facilities provided.

\section{REFERENCES}

1. Smith I. Mycobacterium tuberculosis, pathogenesis and molecular determinants of virulence. Clin Microbiol Rev 2003;16(3):463-96.

2. Iram S, Zeenat A, Hussain S, Wasim Yusuf N, Aslam M. Rapid diagnosis of tuberculosis using Xpert MTB/RIF assay - Report from a developing country. Pak J Med Sci 2015;31(1):105-10.

3. Munir MK, Rehman S, Aasim M, Iqbal R, Saeed S. Comparison of Ziehl Neelson microscopy with GeneXpert for detection of Mycobacterium tuberculosis. IOSR J Dent Med Sci 2015;14(11):56-60.

4. Khatri GR, Frieden TR. Controlling tuberculosis in India. N Engl J Med 2002;347(18):1420-5. 
5. Long R. Drug-resistant tuberculosis. CMAJ 2000;163(4):425-8.

6. Ryu YJ. Diagnosis of pulmonary tuberculosis: Recent advances and diagnostic algorithms. Tuberc Respir Dis (Seoul) 2015;78(2):64-71

7. Marlowe EM, Novak-Weekley SM, Cumpio J, Sharp SE, Momeny MA, Babst A, et al. Evaluation of the Cepheid Xpert MTB/RIF assay for direct detection of Mycobacterium tuberculosis complex in respiratory specimens. J Clin Microbiol 2011;49(4):1621-3.

8. Smith I. Mycobacterium tuberculosis pathogenesis and molecular determinants of virulence. Clin Microbiol Rev 2003;16(3):463-96.

9. Yu MC, Chen HY, Wu MH, Huang WL, Kuo YM, Yu FL, et al. Evaluation of the rapid MGIT TBc identification test for culture confirmation of Mycobacterium tuberculosis complex strain detection. J Clin Microbiol 2011;49(3):802-7.

10. Alvarez-Uria G, Azcona JM, Midde M, Naik PK, Reddy S, Reddy R. Rapid diagnosis of pulmonary and extrapulmonary tuberculosis in HIVinfected patients. Comparison of LED fluorescent microscopy and the
GeneXpert MTB/RIF assay in a district hospital in India. Tuberc Res Treat 2012;2012:932862

11. Zeka AN, Tasbakan S, Cavusoglu C. Evaluation of the GeneXpert MTB/RIF assay for rapid diagnosis of tuberculosis and detection of rifampin resistance in pulmonary and extrapulmonary specimens. J Clin Microbiol 2011;49(12):4138-41.

12. Hillemann D, Rüsch-Gerdes S, Boehme C, Richter E. Rapid molecular detection of extrapulmonary tuberculosis by the automated GeneXpert MTB/RIF system. J Clin Microbiol 2011;49(4):1202-5.

13. Moure R, Muñoz L, Torres M, Santin M, Martín R, Alcaide F. Rapid detection of Mycobacterium tuberculosis complex and rifampin resistance in smear-negative clinical samples by use of an integrated real-time PCR method. J Clin Microbiol 2011;49(3):1137-9.

14. Boehme CC, Nabeta P, Hillemann D, Nicol MP, Shenai S, Krapp F, et al. Rapid molecular detection of tuberculosis and rifampin resistance. N Engl J Med 2010;363(11):1005-15. 